\title{
Impact of COVID-19 on employee engagement in 2020
}

\author{
Shaik Rubeena ${ }^{*}$, Rafia $\mathrm{Naz}^{2}$ \\ ${ }^{1,2}$ Research Scholar, Dept. of Management Research, Andhra University, Visakhapatnam, Andhra Pradesh, India
}

*Corresponding Author: Shaik Rubeena

Email: sk.8rubeena@gmail.com

\begin{abstract}
An environmental uncertainty namely COVID-19 (nCoV: Novel Coronavirus 2019) has drastically changed the entire flow of the world. The COVID-19 pandemic has adversely impacted the functioning and normal lives of the entire world. All the sectors of life, be it economic, social or any other have seen ups and downs. It has been recorded that worldwide, total cases recorded to be $33.4 \mathrm{M}$ out of $23.2 \mathrm{M}$ seems to be recovered. It has been analysed that COVID-19 has also shown its adverse impact on the workplace. In India 6.15M of people recorded to be suffered from COVID-19. The ongoing death rate in India has been recorded to be 96318 (Refer to appendix) and is continued. In this case study, all aspects related to employees including unemployment, layoffs, salary deduction and more are covered.
\end{abstract}

Keywords: Employee engagement, Covid-19, Unemployment, Economic impact.

\section{Introduction}

The COVID-19 pandemic blacked out most of the industries which include entertainment, hospitality, sports, travel, etc. In 2020, it has been recorded that in the U.S. millions of people filled the form of unemployment (Kniffin et al., 2020). It has been recorded that a total of $55 \%$ of the business shutdown were due to COVID-19. Hence, the unemployment rate across the world is uncertainly increased. 7.5 million small-scale businesses are at risk of blackout and this happened due to COVID-19. According to Wanberg (2012) due to the unemployment factor, most people experience stress-related consequences that have been deteriorating the mental health of the people. Across the entire world, financial deprivation is noticed which increases the unemployment rate due to the COVID-19 pandemic.

\section{Objectives of Study}

This case study focuses on the 1. Emerging change in work practices, 2. Sociology and economic impacts (mental wellbeing, operational performance of companies, and unemployment). The sole purpose of the report is to analyse the impact of COVID-19 employment engagement in 2020.

\section{Review of Literature}

Blustein et al. (2020) stated that the COVID-19 pandemic evoked massive unemployment global challenges across the entire world. This research case study, focusing to evaluate how and why COVID-19 shut down the work performance of various companies. Due to COVID-19 lockdown was announced across the world that suddenly stopped all activities. Movement of people from their homes was banned and certain penalties were imposed in the rules so that people strictly follow the rules. The entire work performance of companies came to a standstill. Even, there are some companies like automotive companies in which reliable products are manufactured at the worksites were stopped. Thus, COVID-19 triggered the adversity of the impact of the work performance of the companies. It has been reported that due to unemployment, many starved for food. But when it comes to lockdown, it is also justified because COVID-19 is a communicable disease that spreads across the world and it is the hard step for the government(s) to shut down the entire performance of the countries. Due to COVID-19, several unemployed employees committed suicide because it became difficult for them to survive (Kniffin et al., 2020).

Most of the companies generate low income or revenue due to which firms started minimising the staffing levels. According to meta-analytics, prove that the reduction in staffing deescalates the overall productivity and performance of the companies. It has been recorded that in India approximately 6.1 million youth lose their jobs. As per the survey conducted by CMIE, in March 2020, the unemployment rate in India reach $8.7 \%$. Due to lockdown, the globe will come to the static position that triggers the unemployment and other economic and social-psychological impacts. For example, Virgin Australia is the airline company that faced a great blackout due to COVID-19, it has been analysed that the company fails to implement useful changes within the work environment due to which the company failed to sustain in the market. Due to lockdown the movement of people from one country to another from strictly prohibited by the governments of all countries. Due to great economic loss to countries, companies faced a great financial loss due to which the entire work performance of the company gets reformed uncertainly (Blustein et al., 2020). Because of COVID-19, the social connectedness is lost and people were recommended to WFH (Work From Home) (p \& Shahid, 2020). Unfortunately, this theory is valid for those individuals who are technologically active. But what about non-tech savvy people. Apart from unemployment, unfavorably impacts of COVID-19 are economic inequality, social distancing, and loneliness, stress, and burnout, addiction, etc. It has been analysed that to maintain social distancing, it will be imperative for the working employees to work from home (Lane et al., 2020). When the factories in which the physical presence of employees are required are shut down for the sake of maintaining the social distancing. Thus, it is clear that social distancing also acts as one factor that contributes to the unemployment factor. 
It has been analysed that working from home increases the productivity level of the employee. Like some companies are maintaining daily check-lists to check the performance and productivity of the employees. Working from home allows the employees to flexibly maintain the work schedule. Due to the COVID-19 pandemic to avoid social distancing, companies (those companies which are reliant on the technology) intrusted their employees to work from home. It has been analysed that due to the lack of internet connectivity, laziness among employees, the work of companies is degraded somehow. In fact, after analysing the productivity and performance of employees, companies fired their employees by mapping the inflow of the work ( $\mathrm{p} \&$ Shahid, 2020). It has been noticed that work from the home process is also associated with many disadvantages which include lack of community interaction, lack of communication, difficulty in the management of work, loss of productivity, etc. Thus, work from home decreases the productivity mechanism of the users somehow.

\section{Employee Promotions, Increments}

Only those companies gave promotions, increments, and bonuses to their employees in which the entire work of the company is based on computers. For example, Google, company gave incentives to their respective employees by checking their performance of work. The rate of promotions, increments, bonuses were recorded to be low, this is because, when employees work in the workplace, their performance was manually inspected and checked. In the case of factories where the workload is high employees give their overtime due to which they get incentives but due to social distancing, factories workers were instructed to stay at home due to unemployment factors affects the performance and productivity of the employees (Lane et al., 2020).

It has been analysed that due to work from the home process, most of the owners are not satisfied with their employees. For example, at the workplace, employees discuss the difficulties that they faced in the project, consult with each other, etc. but in case of work from home some of the confusion occurred due to which employees need to rework on the same thing which results in the wastage of time.

\section{Resources for Engaging Employees during a Pandemic}

Various resources can be used by companies to engage their employees for remote communication. By using various platforms companies' staff members and top management committees communicate with their sub-worker and clarify the role and responsibilities to them. Resources used to engage the employees during pandemic include mobile communication (conference calls, video calls, etc), Skype chat and calls, Zoom meetings. It has been analysed that in the case of professional and large-scale organisations to conduct meeting with the employees, top-level management performed zoom meetings and set clear requirements along with them. Overall, it has been analysed that with the use of technology, the communication and interaction among the working employees were established due to which the remote employees understand the mission and vision of the project that the employees are handled. All resources used by the company to manage or engage the employees are associated with the technologies ( $\mathrm{p} \&$ Shahid, 2020).

To support the health of their employees, companies have tried various tools and technological aspects during the crisis. It requires the company's ability to encourage as well as adopt the practices that have been able to maintain their health and improve their well-being. In various parts of the world, the work resumed with the help of productivity and online meeting tools. Flexibility has been introduced by a huge number of companies where virtual social time has been encouraged and hosted by them (Hodder, 2020). Companies are directing staff to work from their home and the remote work program has been made successful by many online apps so that work can be continued with the normal pace.

\section{Video conferencing}

Web conferencing tools like Skype, Zoom, Google Meet is a secure way to navigate the coronavirus pandemic. Getting into work mode from home was not easy without the presence of such effective software. The perks of using a free version or upgrade to a pro one are multiple. Zoom, an online video conferencing platform, is bringing a lot of improvements such as virtual backgrounds to hide chaos, meeting chat can be leveraged to share resources and files, white boarding, and more.

\section{Messaging apps}

Various apps like WhatsApp, project management software, and many more communication channels have been used by the organisation to create a result-oriented environment. Meeting schedules, chat channels and other work-related topics make space for connection on these mediums.

\section{Productivity tools}

Various time tracking software have also taken place in the company's culture. They have become an enhanced way to keep a track of the employees' productivity and justify their working hours and have transparent communication.

\section{Impact on Employment and Labour}

All sectors of businesses and workers have been affected by the sudden emergence of pandemic in the entire world. States have been paying acute attention to strengthening their health care capacity to get prepared for the future in a better way. On the other hand, employees who are a part of non-essential businesses like concert halls, theatres, restaurants, etc. have been facing more strictness from the government ("For community pharmacists to be treated as equals after the COVID-19 pandemic, they must become paid employees of the NHS", 2020). In many parts of the world, people are not allowed to participate in any activity that requires close contact with others (Raišiene et al., 2020).

A universal shutdown of the professional sports industry and others have presented financial challenges for workers. Without pay, sick leave is another reason behind a chaotic mind of workers around the globe. Moreover, the economic ripple effects in these unprecedented times. 


\begin{tabular}{|c|c|c|}
\hline \multicolumn{3}{|c|}{ Cases overview } \\
\hline \multicolumn{3}{|l|}{ Ludhiana } \\
\hline $\begin{array}{l}\text { Total cases } \\
17,477\end{array}$ & $\begin{array}{l}\text { Recovered } \\
15,572\end{array}$ & $\begin{array}{l}\text { Deatins } \\
717\end{array}$ \\
\hline \multicolumn{3}{|l|}{ Punjab } \\
\hline $\begin{array}{l}\text { Total cases } \\
111 \mathrm{~K}\end{array}$ & $\begin{array}{l}\text { Recovered } \\
90,345\end{array}$ & $\begin{array}{l}\text { Deaths } \\
3,284\end{array}$ \\
\hline \multicolumn{3}{|l|}{ India } \\
\hline $\begin{array}{l}\text { Total cases } \\
6.15 \mathrm{M} \\
+82,170\end{array}$ & $\begin{array}{l}\text { Recovered } \\
5.1 \mathrm{M}\end{array}$ & $\begin{array}{l}\text { Deaths } \\
96,318 \\
+1,039\end{array}$ \\
\hline \multicolumn{3}{|c|}{ (1) Worldwide } \\
\hline $\begin{array}{l}\text { Total casses } \\
33.4 \mathrm{M}\end{array}$ & $\begin{array}{l}\text { Recovered } \\
23.2 \mathrm{M}\end{array}$ & $\begin{array}{l}\text { Deaths } \\
1 \mathrm{M}\end{array}$ \\
\hline
\end{tabular}

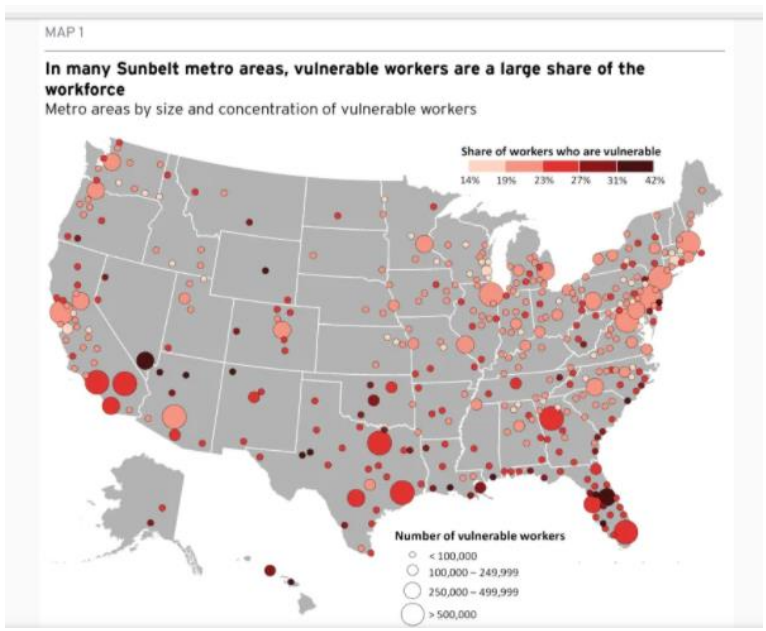

Table- Metropolitan Policy Program at Brookings

Source: https://www.brookings.edu/research/who-are-the-workers-already-impacted-by-the-covid-19-recession/

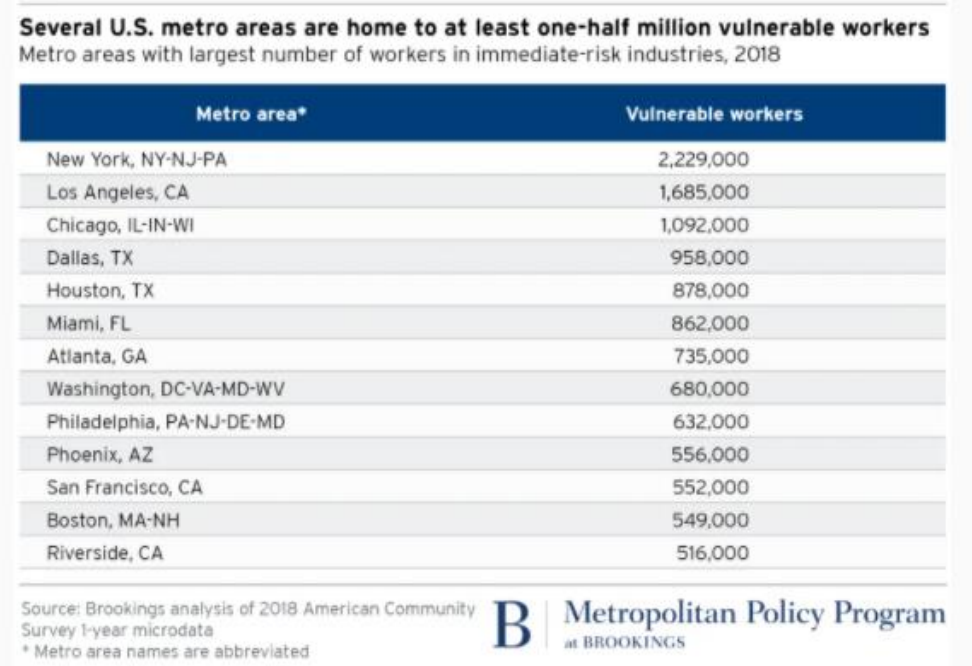




\section{Growth Slump \\ Region's 2020 \\ GDP growth \\ down to 1.8 - \\ $2.8 \%$ from $6.3 \%$ \\ India Assessment \\ Fiscal deficit \\ Growth will rebound \\ projected to widen to to $5 \%$ in FY22 as govt \\ 9\% of GDP in FY21 \\ measures take effect

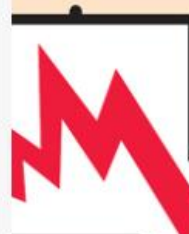 \\ Projections by other agencies \\ Risk Factors

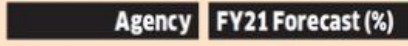 \\ Deceleration will \\ Goldman Sachs 1.6 \\ Moody's 2.5 \\ S\&P 3.5 \\ ADB 4 \\ magnify socio- \\ economic inequalities \\ Pace of poverty \\ reduction likely to be \\ severly impacted}

Source: https://economictimes.indiatimes.com/news/economy/finance/covid-19-causes-severe-disruption-to-indian-economysays-world-bank/articleshow/75104474.cms

\section{Education Industry}

Not only the students but also the teachers are having an equally difficult time making students understand the concepts through online classes. To combat the situation, most of the schools and colleges are using pre-recorded videos. It helps them get a wide range of options like animations and graphics to convey a message/concept in a better way (Spurk \& Straub, 2020). Moreover, those taking home tuitions and coaching have to upgrade their teaching methods online otherwise they may be pushed out of the competition. Hence, the use of the LMS- Learning Management System is on a rise.

\section{Work Space Industry}

Online meetings, conveying meeting schedules over text messages have replaced face-to-face discussions. Low internet speed and no fixed working hours are seemed to be normal during the crisis. It has led to a sudden shift towards allowing work from home to a major fraction of employees. Salaries are also delayed due to reduced productivity at home. Most of the companies are complaining about the delayed projects and hence, salary deductions are being done in almost all the sectors (Lachowska, 2020).

\section{Hospitality Industry}

Restaurants and hotels have been shut down in many parts of the world which is directly affecting the owners and the workers. The financial uncertainty has been hitting all.

The trend of work from home is seeming to continue even after the pandemic. Employers and employees both have their perks related to the module. Employees can save their precious time in traveling and put an extra layer of safety in the future. On the other hand, employers can save a huge chunk of money because they don't need to rent any coworking or individual space. No expenses for office maintenance, near-to-zero electricity bill (Lord, 2020).

The occupational perspectives on working from the home module will change to a huge extent. The other recessions and hard times mostly had affected STEM i.e. Science, Technology, Engineering, and Math and very less impact on other occupations (Kramer \& Kramer, 2020). But Covid-19 has put a widespread effect and also some occupations can also lead to temporal disappearance for example marriage halls, hotels. Occupational mobility and economic growth are interrelated terms. The factors that are associated with the positive and negative changes in the labour market are termed out to be occupational groups, sectors of the economy, the economic system also including the labour market (Bennet, 2015).

\section{Findings}

The sudden outbreak of the COVID-19 pandemic has put the life on a standstill. All the sectors of life such as capital markets, aviation, tourism, retail, MSMEs, and many more. Due to the restrictions on international and internal mobility, there has been a decrease in the generated revenues which counted to be $9.2 \%$ of the GDP. The GDP growth rate has been adversely affected due to the lockdown imposed in the country. The aviation sector has fallen by as much as USD 1.56 billion. In March, oil plummeted to the biggest low in the past 18 years. It fell to as low as $\$ 22$ per barrel which then resulted in a withdrawal of USD 571.4 million by FPIs (Foreign Portfolio Investors). The huge decline in the revenues led to a decrease in global growth from $2.9 \%$ to $2.4 \%$. The growth rate of the country went down to $3.1 \%$ for the fourth quarter of 2020 as per the statements given by the Ministry of Statistics (Dhamija, 2020).

The impact on the Global GDP of a pandemic like a coronavirus, $\mathrm{WHO}$ has estimated it to be from $2.2 \%$ to $4.8 \%$. The cost of lockdown due to the pandemic has cost nearly USD 120 billion or 4\% of GDP ("India's GDP grows 3.1\% in the fourth quarter, 4.2\% in FY20", 2020). The crisis has transformed into labor and economic market shock where it has impacted the production of goods and services (supply), and consumption and investment (demand). Many huge regulations like the International Monetary Fund have termed COVID-19 as the worst economic fallout since the times of 
the Great Depression. Also, it is said to bring extraordinary uncertainty not only about the impact, depth but also about the duration for which it would continue.

Moreover, according to the rating agencies, the growth of India for the next FY2021 might hit the lowest in the past three decades. Many even say that this could be counted as the worst recession that India has hit after its Independence in 1947. All-in-all, the situations created by the pandemic would take years to neutralize and get back on track (Kaminer, 2020).

\section{Suggestions}

The pandemic has brought very uncertain times for employees. Resulting in that the stress levels are also hyped. One of the best tips to get them more engaged during the times of uncertainty is to teach them how to stay calm. Managing difficult situations is one of the best therapies to equip oneself with the power to fight it. Family communication channels should be channelised so that they can get family updates very easily in case of any emergency. More planning is required when employees are not working from the office. Keeping everything under control when half or more people are working from remote areas have a large number of challenges. These can be eased with the help of introducing a planning routine for everyone. A 15-minute session can help and give you a better understanding of where do you stand up. The team leader can take a quick session where all the updates, daily metrics, and the problems faced by the team can be talked about. It would help them to speak out about their experience while adopting a new module of work. Some fun activities can boost their energy levels. Engaging family and kids too can encourage involvement. A word of appreciation always works.

\section{Future Scope}

Not only this, but all should be prepared for the future pandemics and crisis. Advancements in related field of technology and paying attention to what's nature is saying to the mankind are important aspects that can help fight these.

\section{Conclusion}

COVID-19 has been impacting all parts of life and employees have been facing various things from salary deductions to layoffs. Work from home is also a challenge for many. It a chaotic time for everyone no matter what level of the hierarchy it is, employees, managers, and leaders, and owners. Normalcy should be maintained like encouraging employees for their effortless work even during the tough times.

\section{Source of Funding}

None.

\section{Conflict of Interest}

The authors declare that there is no conflict of interest.

\section{References}

1. Blustein D, Duffy R, Ferreira J, Cohen-Scali V, Cinamon R, Allan B. Unemployment in the time of COVID-19: A research agenda. J Vocational Behav, 2020;119:103436. https://doi.org/10.1016/j.jvb.2020.103436

2. Kniffin K, Narayanan J, Anseel F, Antonakis J, Ashford S, Bakker A, et al. COVID-19 and the Workplace: Implications, Issues, and Insights for Future Research and Action. 2020. https://doi.org/10.31234/osf.io/gkwme

3. Lane I, Mullen M, Logan D. Working from Home during the COVID-19 Pandemic: Tips and Strategies to Maintain Productivity \& Connectedness. Psychiatry Inf Brief. 2020;17(5). doi.org/10.7191/pib.1145

4. Shareena P, Shahid M. Work from home during COVID-19: Employees perception and experiences. Retrieved 1 October 2020, from

https://www.researchgate.net/publication/341459773_Work_fr om_home_during_COVID-

19_Employees_perception_and_experiences.

5. Wanberg C. (2012). The Individual Experience of Unemployment. Ann Rev Psychol., 2012;63(1):369-96. doi.org/10.1146/annurev-psych-120710-100500

6. Dhamija V. India after the End of COVID-19 Lockdown. SSRN Electron J. 2020.

doi.org/10.2139/ssrn.3697931

7. For community pharmacists to be treated as equals after the COVID-19 pandemic, they must become paid employees of the NHS. 2020. https://doi.org/10.1211/pj.2020.20208087

8. Hodder A. New Technology, Work and Employment in the era of COVID-19: reflecting on legacies of research. New Technol, Work Employ. 2020. doi.org/10.1111/ntwe.12173

9. India's GDP grows $3.1 \%$ in fourth quarter, $4.2 \%$ in FY20. The Week. (2020). Retrieved 30 September 2020, from https://www.theweek.in/news/biz-tech/2020/05/29/indias-gdpgrows-31-in-fourth-quarter-42-in-fy20.html.

10. Kaminer, D. (2020). Discrimination against Employees without COVID-19 Antibodies. SSRN Electron J. doi.org/10.2139/ssrn.3593113

11. Kramer A, Kramer K. The potential impact of the Covid-19 pandemic on occupational status, work from home, and occupational mobility. J Vocat Behav. 2020;119:103442. doi.org/10.1016/j.jvb.2020.103442

12. Lachowska M. What Is the Likely Impact of Proposed COVID-19 Stimulus Payments?. Employ Res. 2020;27(2):5-5. doi.org/10.17848/1075-8445.27(2)-4

13. Lord P. Incentivising Employment during the COVID-19 Pandemic. SSRN Electron J. 2020. doi.org/10.2139/ssrn.3573176

14. Raišienè A, Rapuano V, Varkulevičiūte K, Stachová K. Working from Home-Who Is Happy? A Survey of Lithuania's Employees during the COVID-19 Quarantine Period. Sustainability. 2020;12(13):5332. doi.org/10.3390/su12135332

15. Spurk D, Straub C. Flexible employment relationships and careers in times of the COVID-19 pandemic. $J$ Vocat Behav. 2020;119:103435. doi.org/10.1016/j.jvb.2020.103435

How to cite this article: Rubeena S, Naz R. Impact of COVID-19 on employee engagement in 2020. J Manag Res Anal. 2020;7(4):137-41. 